\title{
Evaluation of Gas Phase Dispersion in Flotation under Predetermined Hydrodynamic Conditions
}

\author{
Anna Młynarczykowska ${ }^{1, *}$, Konrad Oleksik $^{1}$, and Klaudia Tupek-Murowany ${ }^{1}$ \\ ${ }^{1}$ AGH University Science and Technology, Faculty of Mining and Geoengineering, \\ A. Mickiewicza Av. 30, 30-059 Krakow, Poland
}

\begin{abstract}
Results of various investigations shows the relationship between the flotation parameters and gas distribution in a flotation cell. The size of gas bubbles is a random variable with a specific distribution. The analysis of this distribution is useful to make mathematical description of the flotation process. The flotation process depends on many variable factors. These are mainly occurrences like collision of single particle with gas bubble, adhesion of particle to the surface of bubble and detachment process. These factors are characterized by randomness. Because of that it is only possible to talk about the probability of occurence of one of these events which directly affects the speed of the process, thus a constant speed of flotation process. Probability of the bubble-particle collision in the flotation chamber with mechanical pulp agitation depends on the surface tension of the solution, air consumption, degree of pul aeration, energy dissipation and average feed particle size. Appropriate identification and description of the parameters of the dispersion of gas bubbles helps to complete the analysis of the flotation process in a specific physicochemical conditions and hydrodynamic for any raw material. The article presents the results of measurements and analysis of the gas phase dispersion by the size distribution of air bubbles in a flotation chamber under fixed hydrodynamic conditions. The tests were carried out in the Laboratory of Instrumental Methods in Department of Environmental Engineering and Mineral Processing, Faculty of Mining and Geoengineerin, AGH Univeristy of Science and Technology in Krakow. Key words - cell flotation, air bubbles distribution, bubble size distribution, empirical model.
\end{abstract}

\section{Introduction}

In the process of flotation air bubbles play an essential role which allow mineral particles to rise towards the flotation concentrate, and their size, quantity, and quality determine the final enrichment effect. Due to the fact that the mineralization of air bubbles is a prerequisite for the flotation act, from a practical point of view, the process of stable particle-gas bubbles aggregates formation in the enrichment chamber is a crucial research problem. Because the flotation process takes place under turbulent conditions, the results of the enrichment depend on a number of random factors [1]. The major factors include the impact of a mineral particle with the air bubble, their persistent adhesion, as well as the possible detachment process that results in the disintegration of persistent aggregates of particle-gas bubble [2]. Because

* Corresponding author: mindziu@agh.edu.pl 
those events occur at random we may discuss the probability of such an occurrence which influences the flotation velocity.

There are numerous models which connect the flotation constant speed with the phenomena inside the enrichment chamber. One of the models developed by Yoon and Luttrell [3] is the probability of a particle colliding with a gas bubble, which is dependent on the quotient of their size and represented by the formula [4]:

$$
P_{c}=A\left(\frac{D_{p}}{D_{b}}\right)^{2}
$$

$A$ - constant, dependent on the Reynolds number value for the bubble,

$D_{p}$ - particle diameter,

$D_{b}-$ bubble diameter.

Bear in mind the probability of such a collision will be a random variable due to the fact that the size of the objects are also random variables [4]. Another model developed by Varbanov, Forssberg and Hallin [5] is the correlation between the flotation reaction speed and the angle of wetting the hydrophobic graig, grain and bubble diameter, as well as gas flow rate in the flotation chamber, and the chamber cross-sectional area, which has been represented by the formula:

$$
k=\frac{3 Q R_{p}(1-\cos \theta)}{4 \pi S R_{b}^{2}}
$$

where:

$\theta$ - equilibrium contact angle of the particle,

$Q$ - gas flow rate in the flotation chamber $\left[\mathrm{m}^{3} / \mathrm{s}\right]$,

$S$ - flotation chamber cross-sectional area,

$R_{b}$ - gas bubble radius,

$R_{p}$ - particle radius [4].

Thus, it can be seen that the key factor influencing the achieved effects of enrichment is the size of particles and gas bubbles, and thus the mineralization of air bubbles, which depends on a number of hydrodynamic and physicochemical parameters prevailing in the enrichment work space. Therefore, it is necessary to analyze the dispersion properties of the gas phase, namely: the distribution of the size of the resulting gas bubbles [6]. If the gas bubble would be too small and completely mineralized, its buoyant force would be much less than the gravity of the resulting aggregate, which would lead to its drowning [4]. Because the size of the resulting air bubbles depends on the surface tension of the solution, which varies depending on the type and amount of added surfactant [7] as well as the characteristics of the flotation machine such as the amount of air being dispensed per unit of time, and rotor speed. Brozek and Mlynarczykowska [4] have defined a formula for calculating the minimum size of the bubble:

$$
D_{b \min }=\frac{\pi\left(\rho_{s}-\rho_{c}\right) D_{p}}{\rho_{c}}
$$

where:

$D_{b}-$ bubble diameter,

$\rho_{s}-$ density of particle under flotation, 
$\rho_{c}-$ liquid density,

$D_{p}-$ particle diameter.

Thus the minimum bubble size depends on the size and density of the floated mineral particles. Nevertheless, it should be noted that during the process the particle-bubble aggregate is under constant central resistant force, which will result in the calculated value of the minimum value of the gas bubble size should be slightly higher [4].

Determining the appropriate size of the air bubble for a given material allows you to select the appropriate operating conditions of the floatation machine and facilitate the interpretation of the enrichment process under certain hydrodynamic and physicochemical conditions [7]. The likelihood of attaching the flotation particles to the air bubble increases as the dimensions of the air bubble increase. Hence, it can be concluded that the degree of aeration of the flotation suspension is most advantageous when the optimal saturation of the suspension with air bubbles is obtained, with maximum dispersion [8]. As a result, the size of air bubbles and airflow affect the effectiveness of the flotation process [9-11]. Smaller gas bubbles reduce the probability of detaching the solid phase from the gas phase and increase the probability of collisions and adhesions, while larger gas bubbles ensure that the aggregates of the particle-gas bubbles ascend [11].

The size of the fed particles and the gas bubbles generated in the flotation chamber are distributed in a certain type, which are useful for analyzing the flotation process. The distribution of these quantities and the state of parameters depend on the following factors: rotor speed, amount of air supplied per time unit, method of air delivery to the flotation chamber (depending on the construction / type of the flotation machine) and surface tension of the flotation solution. Therefore, the size distribution of air bubbles depends on how they are formed and under turbulent conditions is log-normal. This is confirmed by studies in which the log-normal distribution best described the obtained results of bubble size measurements [12].

Grau and Heiskanen [13] found that the best distribution of gas bubbles was the "upperlimit" distribution, which is a modification of the log-normal distribution. In contrast, Tavlarides and Stamatoudis [14] have shown that log-normal distribution seems to be the most common when describing the distribution of drops size in liquid-liquid dispersion.

The paper presents the results of analyzes of gas phase dispersion in the flotation chamber according to the distribution of air bubbles at specified hydrodynamic conditions. Based on the obtained results Feret and Sauter's diameters were calculated and the histograms along with the three types of distributions, namely Logarithmic, Weibull and Rayleigh, were plotted.

\section{Measurement methodology}

Measurements were made at the Instrument Methods Laboratory of the Department of Environmental Engineering and Material Processing of the Faculty of Mining and Geoengineering of the AGH University of Science and Technology in Krakow, using the FlotMin test stand $[6,7]$. The flotation machine has the ability to automatically control the airflow, rotor speed, maintain constant fluid level and the speed of the scraper, remotely using a specialized Fix software. The study used a cuboid flotation chamber with a symmetrical structure [6]

After filling the working chamber of the flotation machine with water so that the liquid level fills the "Luba Tube" system and determining certain parameters of the flotation machine operation in the form of rotor speed and airflow, measurements were made for the determined sectors of the working chamber of the flotation machine $(0, \mathrm{~A}, \mathrm{~B}, \mathrm{C})$. Once the gas streams had flowed from the tubes, the air bubbles were broken apart by the rotor blades of the flotation machine. Then the resulting air bubbles were directed from the selected flotation chamber 
area using the "Luba Tube" system to the chamber where their image was recorded using the MOTICAM 2300 camera. Since the working chamber is symmetrical (Fig. 2), it is sufficient to test the air bubbles in one of the quarters, with the possibility of referencing the results to the entire space of the flotation chamber.

The image was recorded using the camera and divided into single frames from which the best quality pictures were selected. Selected images were subjected to computer image analysis to determine their size (i.a. Feret's bubble diameter, bubble circumference, bubble surface area). Professional software for qualitative and quantitative image analysis was used for this purpose. The analysis was performed for images at 5 seconds interval.

Thanks to the recording system operation optimization, a quality image suitable for further analysis was obtained. Figure 1 shows: on the left is a photo selected for further analysis, on the right is the same photo with the image analysis already done with the SigmaScan Pro image analysis software.
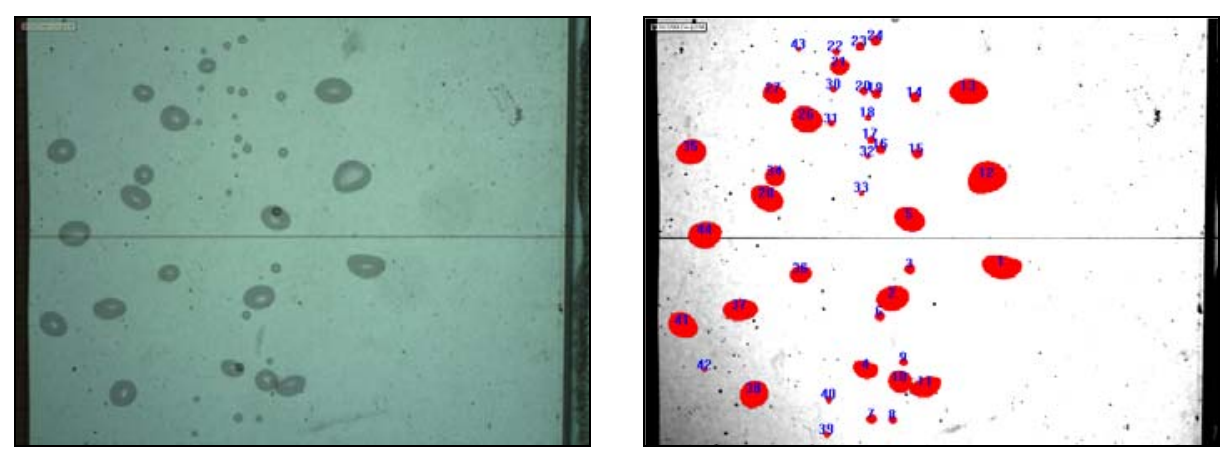

Fig. 1. Sample photo selected for analysis in an image analysis program and the same photo after processing.

\section{Results}

On the basis of the available literature and own analysis of the collected experimental data for mathematical description together with the graphical presentation (Figs. 4-6) of the results obtained using the STATISTICA program, three types of distributions were selected:

- Log-normal,

- Weibull,

- Rayleigh.

The experiment was carried out for two operating parameters of the flotation machine. All of the tests changed the airflow rate $\left(24 \mathrm{~m}^{3} / \mathrm{h}\right.$ and $\left.240 \mathrm{~m}^{3} / \mathrm{h}\right)$ and the rotor speed was constant $(1000 \mathrm{rpm})$. However, in case of measurements performed for cell 0 , in addition to the airflow rate, the rotor speed (1000 rpm and $1350 \mathrm{rpm}$ ) has also been changed so the results obtained from this cell are more numerous and slightly different compared to the other research areas.

Using image analysis software based on two-dimensional images, it calculates the Feret's diameter from the formula:

$$
d=\sqrt{\frac{4 A}{\pi}}
$$

where: $A$ - predicted surface of the bubble in a two-dimensional plane.

Based on experimental data, Sauter's mean diameter of gas bubbles was calculated using the formula: 


$$
d_{32}=\frac{\sum d^{3}}{\sum d^{2}}
$$

Sauter's mean diameter, also referred to as the volume-surface diameter, is expressed in terms of the volume-to-surface ratio, which allows the average diameter of a set of objects of different sizes to be calculated [15]. Therefore, it is an ideal tool for determining the average size of air bubbles dispersed in the flotation chamber.

Table 1 shows the mean Feret's diameter $\left(d_{0}\right)$ database computed using the SigmaScan Pro software and the statistical data for various cell flotation sectors and the operating parameters, as well as the calculated Sauter mean diameter $\left(d_{32}\right)$.

Table 1. The results in each section

\begin{tabular}{|c|c|c|c|c|c|c|c|c|}
\hline $\begin{array}{l}\text { Measurements } \\
\text { number }\end{array}$ & $\begin{array}{l}\text { Std. dev. } \\
\text { of Feret's } \\
\text { diameter }\end{array}$ & $\begin{array}{c}\text { Max. } \\
\text { Feret's } \\
\text { diameter } \\
\boldsymbol{d}_{\max } \\
{[\mathrm{mm}]}\end{array}$ & $\begin{array}{c}\text { Min. } \\
\text { Feret's } \\
\text { diameter } \\
\boldsymbol{d}_{\min } \\
{[\mathrm{mm}]}\end{array}$ & $\begin{array}{c}\text { Mean } \\
\text { Feret's } \\
\text { diameter } \\
d_{0} \\
{[\mathrm{~mm}]}\end{array}$ & $\begin{array}{c}\text { Mean } \\
\text { Sauter's } \\
\text { diameter } \\
d_{32} \\
{[\mathrm{~mm}]}\end{array}$ & $\begin{array}{l}\text { Rotor } \\
\text { speed } \\
(\omega) \\
{[\text { rpm] }}\end{array}$ & $\begin{array}{c}\text { Gas } \\
\text { flow-rate } \\
{\left[\mathbf{d m}^{3} / \mathbf{h}\right]}\end{array}$ & Section \\
\hline 1449 & 0,8223 & 4,7555 & 0,2393 & 1,0014 & 2,3596 & 1000 & 24 & \multirow{2}{*}{ "0" } \\
\hline 650 & 1,0504 & 5,543 & 0,3696 & 2,3028 & 3,1397 & 1350 & 240 & \\
\hline 1901 & 0,7476 & 4,4689 & 0,2816 & 1,553 & 2,1993 & 1000 & 24 & \multirow{2}{*}{ “A” } \\
\hline 2008 & 0,7404 & 6,0885 & 0,6011 & 2,8139 & 3,1933 & 1000 & 240 & \\
\hline 860 & 0,5984 & 4,2718 & 0,474 & 1,6728 & 2,1231 & 1000 & 24 & \multirow{2}{*}{ “B” } \\
\hline 1406 & 0,7459 & 5,1487 & 0,7683 & 2,6557 & 3,0633 & 1000 & 240 & \\
\hline 890 & 0,8464 & 4,7615 & 0,3983 & 1,8435 & 2,6038 & 1000 & 24 & \multirow{2}{*}{ "C" } \\
\hline 1262 & 0,8670 & 6,3311 & 0,9934 & 3,2678 & 3,6930 & 1000 & 240 & \\
\hline
\end{tabular}

Histograms of Feret diameters for air bubbles together with the adjustment of the lognormal, Rayleigh and Weibull probability distribution for the flotation with:

- Fig. 2. Section 0 gas flow-rate $24\left[\mathrm{dm}^{3} / \mathrm{h}\right]$, rotor speed $1000[\mathrm{rpm}]$;

- Fig. 3. Section 0 gas flow-rate $240\left[\mathrm{dm}^{3} / \mathrm{h}\right]$, rotor speed $1350[\mathrm{rpm}]$;

- Fig. 4. Section A gas flow-rate $24\left[\mathrm{dm}^{3} / \mathrm{h}\right]$, rotor speed $1000[\mathrm{rpm}]$;

- Fig. 5. Section A gas flow-rate $240\left[\mathrm{dm}^{3} / \mathrm{h}\right]$, rotor speed $1000[\mathrm{rpm}]$;

- Fig. 6. Section B gas flow-rate $24\left[\mathrm{dm}^{3} / \mathrm{h}\right]$, rotor speed $1000[\mathrm{rpm}]$;

- Fig. 7. Section B gas flow-rate $240\left[\mathrm{dm}^{3} / \mathrm{h}\right]$, rotor speed $1000[\mathrm{rpm}]$;

- Fig. 8. Section C gas flow-rate $24\left[\mathrm{dm}^{3} / \mathrm{h}\right]$, rotor speed 1000 [rpm];

- Fig. 9. Section C gas flow-rate $240\left[\mathrm{dm}^{3} / \mathrm{h}\right]$, rotor speed 1000 [rpm].
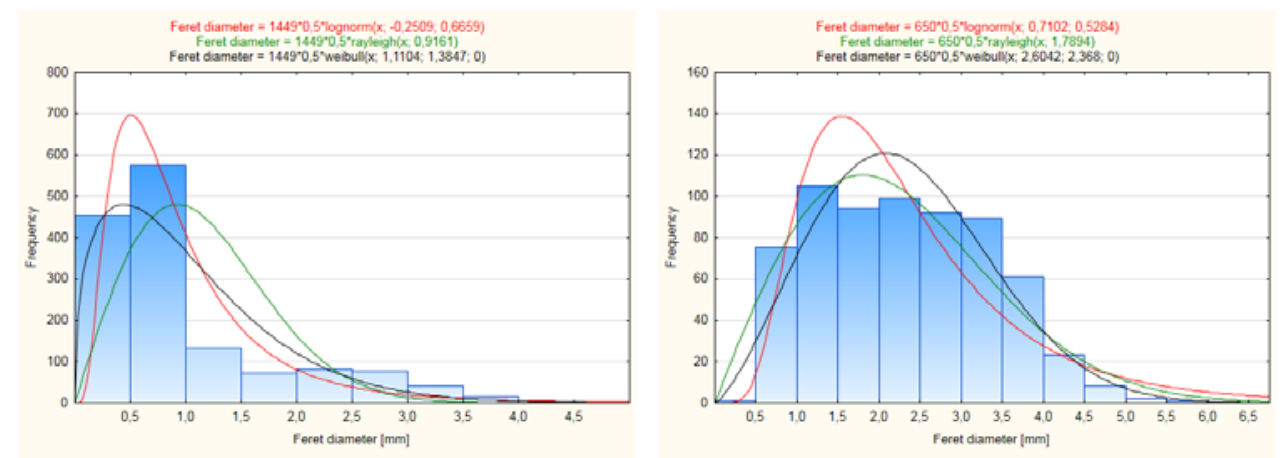

Fig. 2. Section 0 gas flow-rate $24\left[\mathrm{dm}^{3} / \mathrm{h}\right]$, rotor speed $1000[\mathrm{rpm}]$

Fig. 3. Section 0 gas flow-rate $240\left[\mathrm{dm}^{3} / \mathrm{h}\right]$, rotor speed $1350[\mathrm{rpm}]$ 


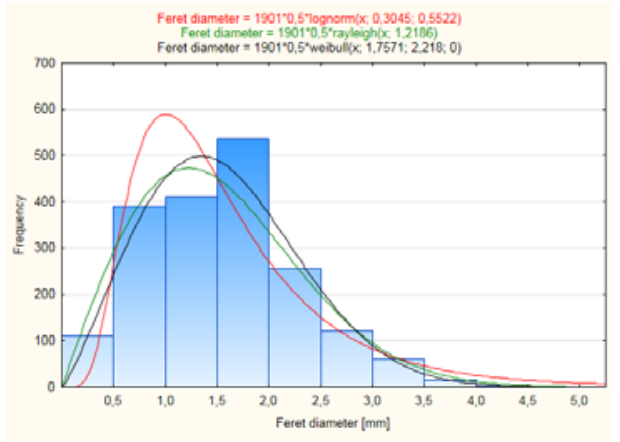

Fig. 4. Section A gas flow-rate $24\left[\mathrm{dm}^{3} / \mathrm{h}\right]$, rotor speed $1000[\mathrm{rpm}]$

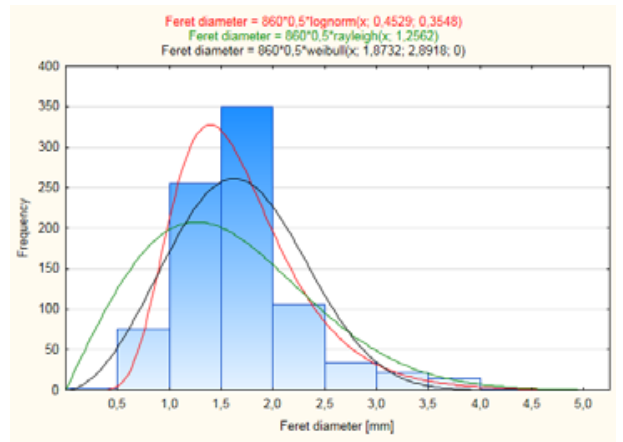

Fig. 6. Section B gas flow-rate $24\left[\mathrm{dm}^{3} / \mathrm{h}\right]$, rotor speed $1000[\mathrm{rpm}]$



Fig. 8. Section $\mathrm{C}$ gas flow-rate $24\left[\mathrm{dm}^{3} / \mathrm{h}\right]$, rotor speed 1000 [rpm]

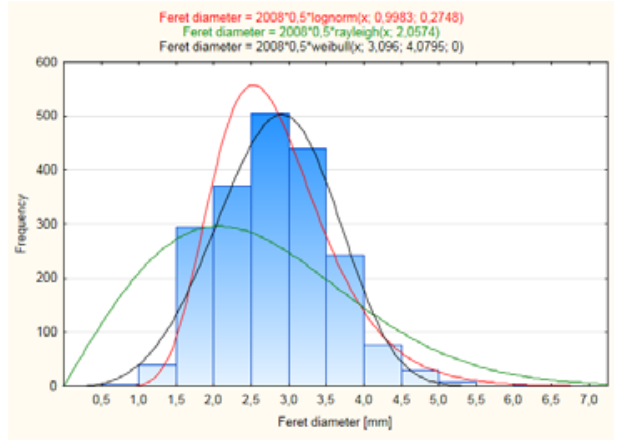

Fig. 5. Section A gas flow-rate $240\left[\mathrm{dm}^{3} / \mathrm{h}\right]$, rotor speed $1000[\mathrm{rpm}]$

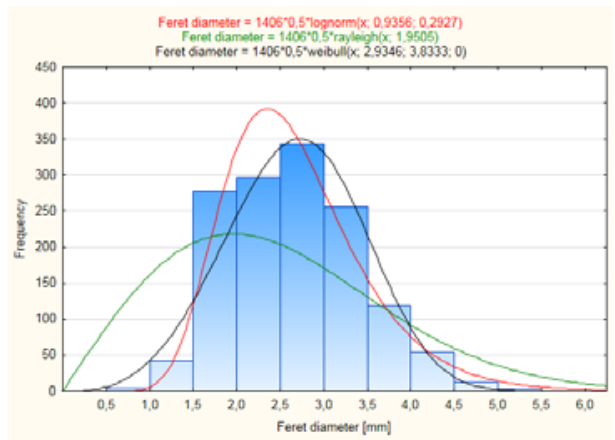

Fig. 7. Section B gas flow-rate $240\left[\mathrm{dm}^{3} / \mathrm{h}\right]$, rotor speed $1000[\mathrm{rpm}]$

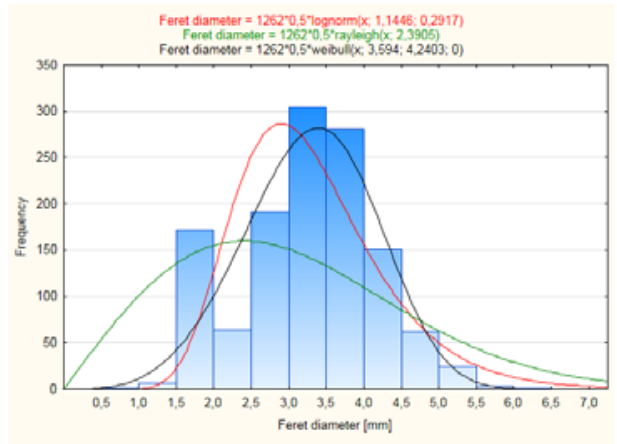

Fig. 9. Section $\mathrm{C}$ gas flow-rate $240\left[\mathrm{dm}^{3} / \mathrm{h}\right]$, rotor speed $1000[\mathrm{rpm}]$

\section{Summary}

By analyzing the distribution of determined values for individual sectors, it may be claimed that the bubbles mean Feret's diameter at minimum aeration of $24 \mathrm{dm}^{3} / \mathrm{h}$ of the working chamber is in the range of $1.0014 \mathrm{~mm}$ to $1.8435 \mathrm{~mm}$ and at maximum aeration of $240 \mathrm{dm}^{3} / \mathrm{h}$ is higher and in the range of $2.3028 \mathrm{~mm}$ to $3.2678 \mathrm{~mm}$. Under the same conditions, the largest population was observed for cell A and the smallest for cell 0. 
At the maximum aeration of the chamber $\left(240 \mathrm{dm}^{3} / \mathrm{h}\right)$ the maximum number of bubbles reaches the size of Feret's diameter from 1.5 to $4.0 \mathrm{~mm}$, and it can be concluded that the air bubbles produced are stable and have a stable shape similar to a ball. With a minimum aeration of $24 \mathrm{dm}^{3} / \mathrm{h}$, the vast majority of bubbles are within the Feret's diameter range of $0.5 \mathrm{~mm}$ to $3 \mathrm{~mm}$. The widest range of Feret's diameter values is among the bubbles in sector 0 , which, combined with a small population, indicates that a small, poorly dispersed portion of air has entered the flotation chamber.

Taking into account the values of the designated Sauter's and Feret's mean diameters for individual sectors of the flotation chamber, a similar increase in the air bubble diameter size along with increasing aeration can be noted. In the case of minimal aeration of the work chamber of $24 \mathrm{dm}^{3} / \mathrm{h}$, Sauter's mean diameter is in the range of $2.1231 \mathrm{~mm}$ to 2.6038 $\mathrm{mm}$, while with aeration of $240 \mathrm{dm}^{3} / \mathrm{h}$ from $3.0633 \mathrm{~mm}$ to $3.6930 \mathrm{~mm}$. Thus, it is noted that in both cases of the enrichment chamber aeration the smallest Sauter's mean diameter was obtained for cell B and the largest for cell C, where the population value varied slightly.

Charts 2 to 9 present histograms along with 3 distributions (logarithm-normal, Weibull, Rayleigh) selected from available literature and own analysis. Experimental distributions were verified with empirical distributions and their compatibility with the Chi-squared test was contrasted using the STATISTICA program. Graphs comparing experimental and empirical distributions and in the probability-probability system were also compiled.

Due to the large number of verifications carried out in the article, only two such graphs for cell A were shown as examples (the chamber aeration was $240 \mathrm{dm}^{3} / \mathrm{h}$, rotor speed 1.000 rpm)-Figures 10 and 11 .

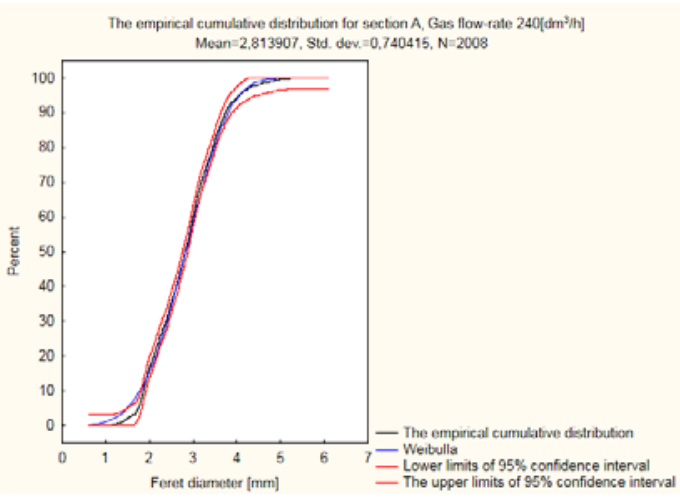

Fig. 10. The empirical cumulative distribution for section A, gas flow-rate $240\left[\mathrm{dm}^{3} / \mathrm{h}\right]$

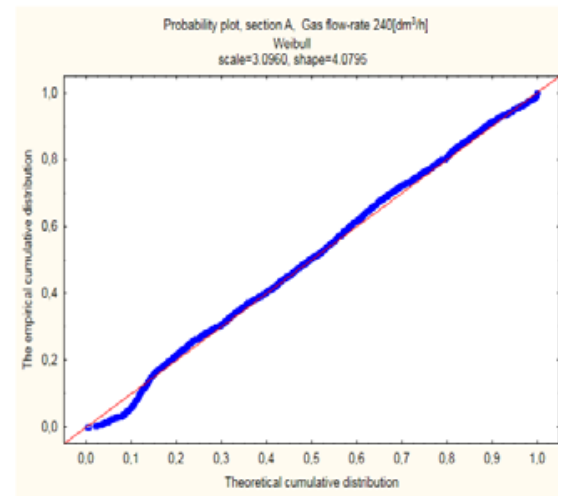

Fig. 11. Probability plot for section A, gas flow-rate $240\left[\mathrm{dm}^{3} / \mathrm{h}\right]$

The results of the verification and the tests are ambiguous, because in 4 cases (Figs. 2, 6-8) the logarithmic distribution fits to the real distributions best, and in other 4 cases (Figs. 3-5, 9). Weibull distribution seems to be a match. However, for the extreme sectors 0 and C, we can observe that the best fit for the small aeration of $24 \mathrm{dm}^{3} / \mathrm{h}$ is with the logarithmic distribution, while for high aeration of $240 \mathrm{dm}^{3} / \mathrm{h}$ Weibull distribution seems to be most matching. In addition, it is worth noting that differences in matching of these distributions are insignificant.

\section{Conclusion}

The performed analysis of the results and verification of the analyzed distributions confirms some of the earlier reports [12-14] of a good reflection of the experimental data by log-normal distribution and Weibull distribution. 
On the basis of the results obtained, it can be stated that:

- the increase in rotor speed results in a decrease of gas bubbles dimensions and at the same time increases their amount,

- at increased rotor speed, increasing the aeration results in an increase in the size of the gas bubbles,

- aeration intensity influences the shape of the resulting air bubbles (the greater the airflow, the more irregular the shape of the air bubbles formed).

\section{Acknowledgments}

This work was done as a part of the University of Science and Technology Research Program No. 11.11.100.276. This article is an extension of the presentation at the MEC 2016, 25-28 September 2016, Swieradow-Zdroj, Poland

\section{References}

1. D. Saramak, A. Mlynarczykowska, A. Krawczykowska, Archives of Metallurgy and Materials, 59(3), 951-955 (2014)

2. S. Blaschke. Przeróbka mechaniczna kopalin, Część II. Wydawnictwo Śląsk, Katowice (1984)

3. R.H. Yoon, G.H. Luttrell, Miner. Process. Extr. Metall. Rev. 5, 101-122, 751-756 (1989)

4. M. Brozek, A. Mlynarczykowska, Arch. Min. Sci., 57, 3, 729-740, (2012)

5. R. Varbanov, E. Forssberg, M. Hallin, Int. J. Miner. Process., 37, 27-43 (1993)

6. A. Mlynarczykowska., A. Nyrek, K. Oleksik, IM, 1(35), 181-188 (2015)

7. A. Mlynarczykowska, K. Oleksik, IM, 18, nr 1, 257-262 (2017)

8. S. Blaschke. Procesy technologiczne $w$ przeróbce kopalin użytecznych. Wydawnictwo „AGH”, Kraków (1987)

9. F.F. Lins, R. Adamian, Minerals Engineering, 6, 267-277 (1993)

10. H.J. Schulze, Coagulation and flocculation theory and applications, B. Dobias (Ed.). Chapter 7. Flotation as a heterocoagulation process: Possibilities of calculating the probability of flotation. Marcel Dekker Inc., New York (1993)

11. D. Tao, Sep. Sci. Technol. 39(4), 741-760 (2004)

12. L. Vinnett, F. Contreras, J. Yianatos, 2011. Gas dispersion pattern in mechanical cells. Mineral Engineering, 26, 80-85 (2012)

13. R.A. GRAU, K. Heiskanen, Minerals Engineering, 18, 1164-1172 (2005)

14. L. Tavlarides, M. Stamatoudis, Advances in Chemical Engineering 11, 199-273 (1981)

15. P.B. Kowalczuk, J. Drzymała, Particulate Science and Technology, vol. 34, issue 6, 645-647 (2016) 